\title{
Sarmiento e o romantismo no Rio da Prata
}

\author{
DIEGO A. MOLINA
}

"En la pampa hay que completar por el arte la obra de Dios."

Sarmiento

\section{Ponto de partida. Reverberações transatlânticas}

A PÓS A Revolução Francesa, as decorrentes invasões napoleônicas na Europa motivaram alianças, movimentos, guerras e até fugas, como a da família real portuguesa que, em 1808, amedrontada pela ameaça francesa, instalou sua corte no Rio de Janeiro. A Espanha, por sua vez, viu-se obrigada a optar por um dos dois maiores adversários do conflito: França e Inglaterra. Se Portugal aliou-se a esse país, pois de fato a marinha britânica custodiou a mudança transatlântica da família real, Carlos IV da Espanha escolheu o lado de Napoleão, que em 1808 lhe exigira a abdicação ao trono em favor do seu filho Fernando VII, o príncipe de Astúrias. Cabe lembrar que tal alinhamento político dos países da Península Ibérica tinha antecedentes recentes importantes. Uns anos antes, a estrepitosa derrota marinha na batalha de Trafalgar de 1805 dos aliados franco-espanhóis contra os britânicos deixou em evidência a supremacia da Inglaterra como nova potência ultramarina. Em 1806 e 1807, haviam ocorrido as invasões inglesas ao Rio da Prata. A estratégia britânica, que já tinha dados bons resultados ao tomar pela força as costas do Cabo de Boa Esperança, na África, e a Índia, além de dominar amplamente os mares do globo, era apoderar-se dos portos de Buenos Aires e de Montevidéu para garantir o domínio comercial em territórios do velho império espanhol e acabar assim com três séculos de supremacia ibérica.

Com o agravamento dos conflitos internos da Espanha, cujo ápice foi a condução ao trono de José I Bonaparte, o irmão de Napoleão, o poder colonial espanhol começava seu lento declínio. A notícia da deposição e cativeiro de Fernando VII foi recebida em Buenos Aires com surpresa, por parte de alguns, e entusiasmo, por parte de outros. A chamada Revolução de Maio de 1810 teve início, então, sem um programa, dando-se simplesmente como necessidade conjuntural. Os acontecimentos sociopolíticos que configuraram tal revolução acabariam, após seis anos de batalhas em quase toda a América do Sul espanhola, com a independência da futura república.

Depois da derrota espanhola, e de alguns anos de caos político e guerras 
civis em todo o território argentino, as províncias unidas do Rio da Prata organizaram uma primeira tentativa de governo unitário, que prefigurou a dicotomia Buenos Aires (porto) versus interior; dicotomia que regeu todo o pensamento político do século XIX na Argentina.Essa primeira tentativa de organização político-institucional fracassará rotundamente, dando lugar a um novo e violento período de guerras civis. Mas em 1822, o Brasil independente de D. Pedro I, ao retomar o velho projeto português de anexar a província Cisplatina a seu território, gerou a desconfiança das facções em litígio e, diante da iminência de uma guerra com o Brasil imperial, e só então, restabeleceu-se uma Constituição unitária e iniciou-se em Buenos Aires o governo de Bernardino Rivadavia. Antes de o conflito armado começar, Rivadavia instaurou uma série de reformas para modernizar a futura capital. Atento às novidades europeias - e a sugestiva correspondência de Rivadavia com o filósofo inglês Jeremy Bentham e com o filósofo francês Antoine Louise Claude Destutt de Tracy o demonstra -, Rivadavia concretizará em 1822 a fundação da Universidade de Buenos Aires. Os programas e os conteúdos das disciplinas ministradas nessa instituição acompanhavam as novidades europeias em matéria de: Ideologia, Direito, Economia Política etc. Foi nessa universidade, e por meio de bolsas outorgadas pelo próprio Rivadavia, que se reuniu e se formou a chamada "geração de 1837", composta por jovens provenientes das províncias do interior e portenhos.

O novo fracasso de organização político-institucional, com a estrepitosa queda de Rivadavia, acusado de ceder diante dos interesses britânicos e do império brasileiro, atiçou os combates entre unitários e federais. Esses dois grupos polarizariam as ideias políticas sobre a organização nacional na Argentina ao longo do século XIX. Um dos momentos mais dramáticos dessa luta ocorreu quando, ao voltar da guerra contra o Brasil imperial, o general Juan Lavalle reinstaurou impulsivamente o poder unitário e mandou fuzilar o governador de Buenos Aires, o federal Manuel Dorrego, aliado de Rosas. Essa morte detonou a retomada ainda mais feroz das guerras civis. Lavalle foi derrotado em abril de 1829, na batalha de Ponte Márquez, pelas forças federais encabeçadas por Juan Manuel de Rosas e Estanislao López, caudillo e governador de Santa Fe. Numa última tentativa de manter a ordem unitária, Lavalle recorreu ao general San Martín, herói das batalhas da independência na Argentina, Chile e Peru, quem, decepcionado pelas continuas e sangrentas guerras civis, decidiu exilar-se. Eis o itinerário violento que levou Rosas ao centro da cena política.

Os primeiros anos da década de 1830 são de cruentas batalhas, de caos político e, sobretudo, de consolidação das figuras dos caudillos e suas montoneras, isto é, milícias rurais armadas. Rosas, em Buenos Aires, López, em Santa Fe, mas, sobretudo, Facundo Quiroga, em La Rioja, serão os atores mais destacados da ideia de federalismo. É necessário esclarecer que por federalismo se entende, nesse contexto, o Pacto Federal de 1831, pacto cujos conflitos encarniçados, ao longo de sua vigência, manteve Rosas no centro da cena política de Buenos Aires até $1852 .{ }^{1}$ Os anos que vão de 1831 a 1852 compõem um projeto político 
inacabado que a historiografia argentina colocou como o primeiro momento, embora violento, de unificação nacional e que seria mais apropriado chamar de Confederação, pois a autonomia dos Estados que a integram se opõe ao centralismo de Buenos Aires. Tal centralismo, apesar de tudo e de todos, acabará prevalecendo, fundamentalmente com Rosas no poder.

\section{A geração de 1837 e o romantismo no Rio da Prata}

O grupo que se reuniu na livraria de Marcos Sastre, em 1837, dando início ao Salão Literário de Buenos Aires, formaria, desde então, uma primeira associação de jovens que tentaria desvendar quais eram, ao menos para eles, os impedimentos que entorpeciam o pretendido progresso nas províncias unidas do Rio da Prata. Entre os integrantes destacam-se: Juan Bautista Alberdi, Juan María Gutiérrez, José Mármol, Félix Frías, Domingo Faustino Sarmiento, incorporado ao grupo posteriormente pela historiografia porque o sanjuanino não participou dessas primeiras sessões. A abertura do Salão esteve a cargo do próprio Marcos Sastre, dono do local e da biblioteca que, como ressalta no seu discurso, continha: "las obras más importantes de la república de las letras, y particularmente las producciones modernas que siguen la marcha del espiritu humano" (in Weinberg: 1977, p.119). O discurso de Sastre é pacato e interesseiro. Glorifica Rosas, tentando oficializar-se: "Porque el actual gobierno es el único conveniente, el único poderoso para allanar los caminos de la prosperidad nacional". Também Alberdi viu em Rosas, ao menos nesse momento, um exemplo a ser imitado. Talvez a federalização progressiva e violenta fosse a causa dos elogios. Vale mencionar, como exemplo, que em 1836 Rosas havia feito por decreto (de 27 de janeiro) uma intervenção na Universidade de Buenos Aires, que estipulava que nenhum aluno poderia receber o título de grau de doutor "sin acreditar previamente, por información sumaria, haber sido obediente y sumiso a las autoridades y adicto a la causa nacional de la Federación" (Weinberg, 1977, p.15).

A figura central da primeira fase de organização do grupo, porém, foi o escritor e poeta Esteban Echeverría, autor das primeiras composições poéticas de caráter nacional e introdutor da ideia de romantismo entre seus pares. Em 1830, ao voltar de sua viagem de estudos na França, o jovem Echeverría converte-se rapidamente em referência para a elite letrada local. Dois motivos imbricados na mesma busca mobilizam esses jovens: por um lado, após a emancipação política da Espanha buscava-se uma emancipação cultural que completasse a independência; por outro, o caos político e a falta de organização institucional requeriam um esforço conjunto para colocar o país no suposto e citado fartamente caminho do progresso. A produção bibliográfica desses primeiros anos dão conta dessa particularidade, isto é: buscava-se realizar no plano intelectual o que no plano material havia se iniciado com a revolução de maio de 1810 , da qual a geração de 1837 se declarava filha. Daí a força e a hegemonia que o romantismo teve entre os jovens argentinos, sobretudo aquele romantismo do qual Hugo tinha qualificado como "o liberalismo na literatura". Dessa conjuntura 
decorre o fato de o grosso da produção romântica dos jovens argentinos tivesse um marcado caráter político que, muitas vezes, deixava num segundo plano as aspirações estéticas.

Ora, quando esses jovens buscam denodadamente as causas do atraso e se apropriam do romantismo como bússola e reservatório teórico e estético, embora manipulado e adaptado, todos os olhares se dirigem à Espanha. O século XIX, após 1810, será marcadamente hispanófobo na Argentina: a ex-metrópole aparece como a causa do atraso e da "barbárie" em que estava submerso o país. Já na primeira versão do hino nacional de 1813 estavam contidas as afrontas contra a realeza espanhola em estrofes alusivas à heráldica real: "a sus plantas rendido um león" (o leão é um dos atributos do escudo espanhol, que se rendia aos pés da nação emergente, segundo o hino de tom belicoso). Sarmiento, Alberdi, Echeverría, todos eles encontraram em Espanha o germe do caos e do atraso; em seus escritos abundam as menções que colocam a Espanha fora do círculo de países europeus; isto é, quando falavam da Europa, excluía-se a Espanha aberta ou implicitamente. Esse jogo de opostos gerou uma lista de características pela qual, mais tarde, os jovens românticos seriam acusados de europeizantes ao colocar o americano do lado da barbárie e só o europeu do lado da civilização. O certo seria dizer que sempre prevaleceu nesses primeiros textos de cunho romántico uma tensão entre ambos os olhares, o que o crítico literário David Viñas resolveu na figura do "olhar estrábico" de Echeverría: um olho na América e outro nas novidades europeias.

O romantismo argentino terá vigor e encontrará seu lugar no exílio, durante a chamada proscrição de seus integrantes, que começa com a perseguição sistemática que Juan Manuel de Rosas realizou de seus adversários políticos por meio de La mazorca, isto é, o braço armado da Sociedade Popular Restauradora, uma espécie de polícia a serviço da causa federalista, cujos métodos crudelíssimos narrará Sarmiento em seu Facundo e Mármol em seu romance Amália, os dois textos mais representativos, junto ao poema "La cautiva" de Echeverría, de toda a produção romântica argentina. No paroxismo dessas perseguições sem trégua, houve algumas semanas de violência exacerbada no final de 1840. Essas semanas, que os românticos chamariam de terror, alcançaram para exercitar a mente de todos os adversário de Rosas - quem havia sido nomeado governador de Buenos Aires e Restaurador das leis com a soma do poder público-, que saíram de Buenos Aires e, mais tarde, das províncias que estavam sob o domínio federal. Tudo o que lembrasse aos unitários foi proibido, sobretudo suas cores, o azul-celeste e o verde, substituídas pelo vermelho (a obrigatória "divisa punzó", isto é, escarlata), cor dos confederados cujo lema era: "Viva a santa Federação! Morram os selvagens Unitários!". Os inimigos de Rosas foram obrigados a retirarem-se da arena política, recluírem-se em outros âmbitos e refugiarem-se em países vizinhos. Esse é o itinerário do êxodo romântico: Sarmiento se instala no Chile, onde escreverá em alguns jornais de importância, lançando seus ataques contra Rosas; Alberdi 
migra à Bolívia e daí viajará para Chile, Uruguai e Europa; Gutiérrez, Echeverría e Mármol se instalam em Montevidéu, principal foco de resistência ao governo de Rosas, pois ali se encontravam os velhos opositores unitários. Mais tarde, Mármol passará mais de seis anos na corte de Rio de Janeiro.

Já em 1838, enquanto Buenos Aires padecia o bloqueio do porto feito pela marinha francesa, que exigia as mesmas vantagens comerciais que Juan Manuel de Rosas outorgara à Inglaterra, os proscritos aproveitarão a visibilidade do conflito e, do exílio, manifestarão todo tipo de ataques contra o "tirano" Rosas. Os ataques se condensavam em panfletos, especialmente, mas também em outras publicações cujos títulos dispensam maiores comentários: o periódico "Muera Rosas!", editado pelos proscritos em Montevidéu em 1841, a poesia "El puñal", na qual José Mármol propunha e incitava a cometer o "tiranicídio", o ensaio, em forma de epístolas, Aglória do tirano Rosas, publicado por Félix Frias em Santiago de Chile em 1847, ou obras do calibre do Facundo. Civilização e barbárie, publicado por Sarmiento no Chile, primeiro como folhetim em 1845 e depois como livro, no mesmo ano.

Mas além das lutas, dos debates e das exaltadas críticas contra Rosas, o que esse grupo de intelectuais inventará é um manancial simbólico de imagens, de tópicos e de tipos nacionais que percorrerão a historiografia argentina até nossos dias. Uma das perguntas que Echeverría se fazia, até mesmo antes do exílio, era como construir uma literatura nacional que carecia de tradição, ou seja, como fundar uma literatura nacional? Echeverría havia utilizado em sua poesia "La cautiva" de 1837 a imagem do deserto como metáfora dos pampas, a extensa planície que se estende de Buenos Aires até a pré-cordilheira dos Andes ao norte e ao sul. Essa comparação, que já aparecia em alguns dos relatos de viajantes ingleses que a partir da abertura do porto em 1810 reativaram suas visitas para explorar as terras americanas em busca de novos mercados para suas manufaturas, levou Sarmiento a articular uma teoria sobre a falta de laço social que propicia o meio. A figura do gaucho, ou dos tipos de gauchos, entrará no imaginário dos românticos como problema e, ao mesmo tempo, como figura local, original. $\mathrm{O}$ território tem assim um papel preponderante nessa construção. O determinismo geográfico opera no temperamento do gaucho de duas maneiras: uma de forma negativa: na medida em que a incomensurabilidade do terreno suscita a ausência de civilização, e outra de forma positiva, na medida em que na relação telúrica com um meio infinito a liberdade do gaucho obtém essa mesma dimensão. A "independência" e a "liberdade" do gaucho estão, então, no solo: a terra, o território argentino, estava destinada a esses bens tão apreciados. Sobre esse deserto, fatalmente destinado à grandeza e à liberdade segundo os românticos, a elite letrada imprimirá seu projeto de nação: “uma nação para o deserto argentino", na precisa metáfora do historiador Tulio Halperín Donghi. Integram-se um cenário - os pampas - e um agente - o gaucho. Eis o imaginário argentino em funcionamento, seu ponto de partida. 
Por outro lado, como todo discurso que compõem um nós outros, "La cautiva" de Echeverría também representou o índio como "o outro", o selvagem que estava fora do projeto civilizatório. E essa exclusão passará do literário ao material ao longo do século XIX, nas campanhas ao deserto, provocando um dos maiores genocídios indígenas perpetuados na América Latina, pois executado por ordem e prepotência do Estado.

Esse romantismo, que poderíamos aglutinar sob a imagem da força centrífuga, pois é realizado de fora, exílio, pensando sempre no centro evocado, Buenos Aires, tem mais de panfletário que de literário. Ora, ainda que só um punhado dessas obras tenha transcendido a mera conjuntura, nenhuma teve o vigor nem animou tantos os debates quanto Facundo de Sarmiento.

\section{Sarmiento por ele mesmo}

Apesar de não ter participado, como mencionamos, do Salão Literário de 1837, Domingo Faustino Sarmiento é o autor mais citado e comentado da primeira metade do século XIX na Argentina. Quase tudo o que dele sabemos, devemos a ele mesmo. Pois exerceu com denodo a autoafirmação desde cedo, ressaltando seu papel histórico e reinventando-se uma e outra vez em escritos autobiográficos. Além disso, Sarmiento é o maior representante argentino do que na época se chamava de self-made man, além de um claro exemplo da possibilidade de ascensão social. Pois sua vida é a recomposição, por momentos pletórica e megalomaníaca, de suas lutas e suas conquistas, desde as origens humildes de menino de província, passando por infinidade de trabalhos menores, como o de mineiro no Chile, o seu percurso intelectual como jornalista e escritor, o seu papel como educador e como teórico da educação, o seu lugar no Exército Grande que derrubou Rosas em 1852, como "boletineiro", aquele que escrevia o boletim do dia a dia do confronto, até chegar à presidência da república (1868-1874).

No primeiro de seus textos autobiográficos, escrito para se defender dos ataques sobre o seu suposto passado espúrio, durante o segundo exílio chileno em 1843, cujo título é, justamente, Mi defensa, Sarmiento (1948, p.6-7) escreve:

He nacido en una provincia ignorante y atrasada, no como cree don Domingo $S$. Godoy, en el barrio de San Pantaleón, sino en el más oscuro todavía, llamado el Carrascal, nombre equivalente a Huangali. He nacido en una familia que ba vivido largos años en una mediocridad muy vecina de la indigencia, y hasta hoy es pobre en toda la extensión de la palabra. Mi padre es un buen hombre que no tiene otra cosa notable en su vida que haber prestado algunos servicios en un empleo subalterno, en la guerra de independencia... Mi madre es el verdadero tipo del cristianismo en su acepción más pura, la confianza en la Providencia fue siempre solución a todas las dificultades de la vida.

Dessa forma, o ponto de partida de Sarmiento já era desfavorável, nasceu numa província "ignorante e atrasada" e a sua família viveu longos anos na pobreza, quase na indigência. Apesar disso, sendo mera estilização ou monumento hiperbólico de sua própria figura, Sarmiento soube recompor-se, pois, em seu 
segundo texto autobiográfico, quando já tinha certo renome na imprensa chilena, como jornalista e como educador, e após a publicação do Facundo e de suas Viagens a Europa, África e Estados Unidos, prévia passagem por Montevidéu e Rio de Janeiro, Sarmiento afirma não só a ideia de que ele é o filho legítimo da Revolução de Maio, apontando para o fato casual de ter nascido em fevereiro de 1811 , isto é, nove meses depois de iniciada a Revolução, mas também forjando para si a ideia de certa linhagem patriótica e democrática:

Mis Recuerdos de Provincia son nada más que lo que su título indica. He evocado mis reminiscencias, he resucitado, por decirlo asi, la memoria de mis deudos que merecieron bien de la patria, subieron alto en la jerarquia de la Iglesia, y honraron con sus trabajos las letras americanas [...] Hay [en su histórico familiar] una nobleza democrática que a nadie puede hacer sombra, imperecedera: la del patriotismo y el talento. Huélgome de contar en mi familia dos historiadores, cuatro diputados a los congresos de la República Argentina, y tres altos dignatarios de la Iglesia. (Sarmiento, s. d., p.5)

Sarmiento começa assim o caminho da autoafirmação que, por momentos, aproxima-se da soberba, e, às vezes, da autocomplacência. Sua figura de autodidata é também citada com frequência, sobretudo o episódio anedótico no qual Sarmiento afirma ter aprendido francês em três semanas. Além de escrever em francês e inglês, bem como traduzir de ambas as línguas, foi, sem dúvidas, um leitor fervoroso, onívoro e atento, assim como um escritor prolífico: publicou artigos, críticas, ensaios, resenhas, panfletos, discursos e interveio em não poucas polêmicas na imprensa chilena, na argentina, na uruguaia, na boliviana e na brasileira. Suas obras completas constam de mais de cinquenta volumes. Ora, existe um divisor de águas na visão de conjunto de Sarmiento, mais do que na sua ideologia, que continuará a ser a do liberalismo oitocentista, pois, durante suas viagens pela Europa (1846-1847), todo o esplendor que tinha idealizado no velho continente decai. Após a revolução de 1848, finalmente, a sua impressão se acentua e os Estados Unidos passam a um primeiro plano em detrimento da Europa barbarizada. A modernidade, a democracia, o associacionismo, tudo o que pretendia para a Argentina, assim que Rosas fosse derrubado, e já em 1845, no Facundo, isso lhe parecia próximo, Sarmiento encontrou nos Estados Unidos, durante sua visita ao país do norte e na assídua leitura do sempre citado Tocqueville. É por isso que Sebreli (2003, p.19) chama Sarmiento de "el ideólogo más lúcido de la burguesía ilustrada" e de um "predicador de la modernidad".

Se os primeiros escritos autobiográficos de Sarmiento ganharam a forma da defesa, o Facundo se levantará como um hábil ataque que, a partir daí, será sua melhor defesa. Ora, ao elaborar o presente político da Argentina de 1845, no exílio chileno, em forma de enigma, o Facundo foi lido, e continua sendo, como um texto edípico. Isto é, apresenta-se um enigma que é o motor do texto: como é possível que uma revolução de independência acabe em guerras civis e na entronização de um tirano sangrento no poder, a esfinge que pairou sobre Buenos Aires, e sobre seu porto. Facundo viria a responder esse enigma. Con- 


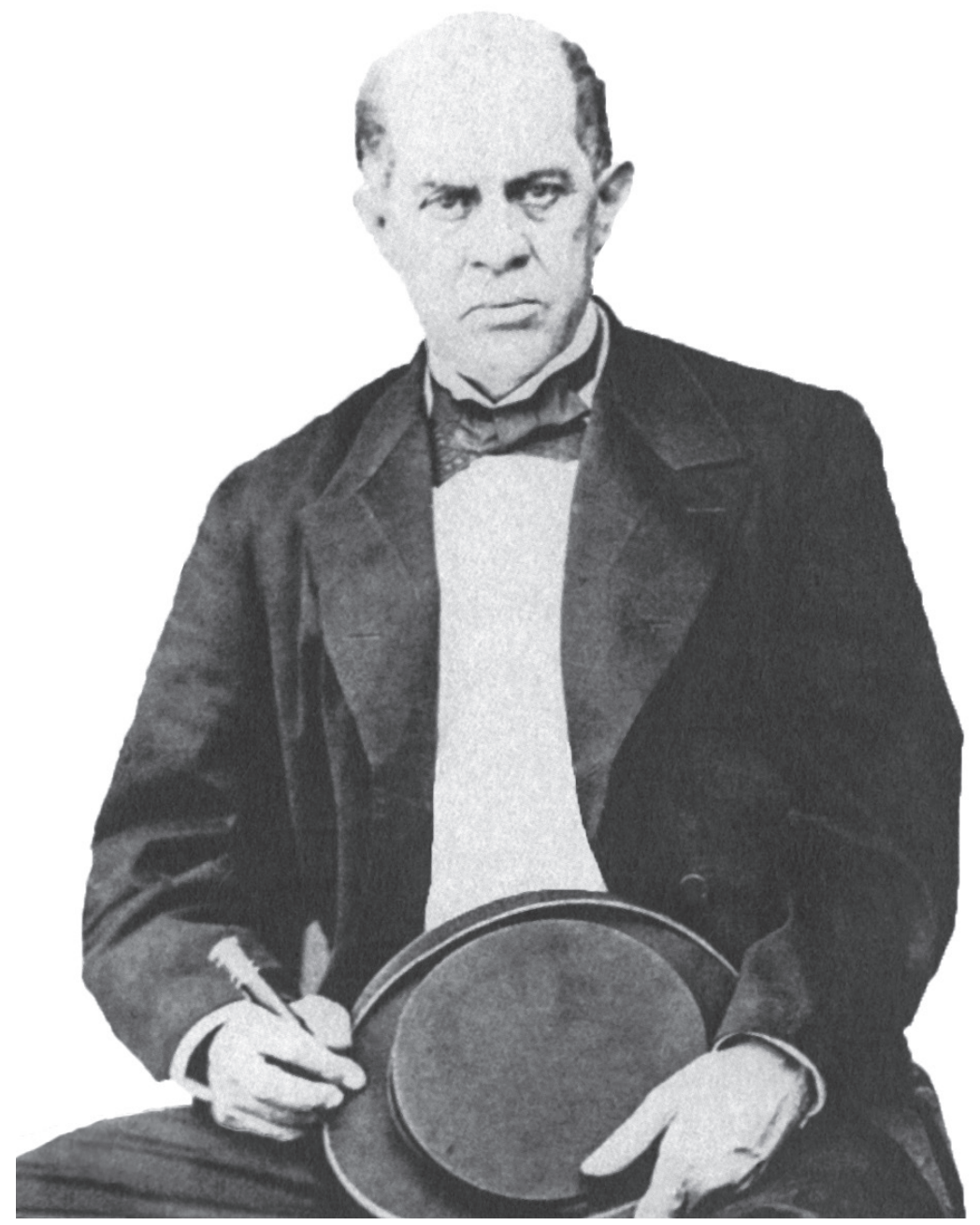

Domingo Faustino Sarmiento (1811-1888).

junturalmente. Contudo, ao explicar os tipos nacionais por meio do determinismo geográfico - os pampas planos e infinitos -, e do determinismo histórico - a colonização espanhola -, Sarmiento inaugura uma tipologia nacional-literária. De fato, seu Facundo será traduzido e comentado, tanto na França quanto na Alemanha e imediatamente depois de sua publicação no Chile, como produção literária americana genuína. Tal leitura sempre agradou Sarmiento, como se observa nas não poucas menções desse particular na sua extensa correspondência. Ou seja, Sarmiento sabia que havia escrito um texto enérgico, com altíssimos momentos estéticos e por isso podia dizer, com modéstia não dissimulada: " $A l$ despedirme de mi buen amigo Montt, le decía yo con aquella modestia que me caracteriza: la llave de dos puertas llevo para penetrar en Paris: la recomendación oficial del gobierno de Chile y el Facundo; tengo fe en este libro" (Sarmiento, 1949, p.130). 


\section{Facundo, civilização e/ou barbárie: dialética ou binômio irreconciliável?}

Como sugerimos, então, se existe um livro representativo de toda a geração romântica de 1837 é, sem dúvida, o Facundo. Civilização e barbárie de Sarmiento. Isso não deixa de ser contraditório por dois motivos: em primeiro lugar, porque Sarmiento, como mencionamos, não participou das reuniões do Salão Literário de 1837 e só conheceu os integrantes desse grupo no exílio; em segundo lugar, porque além disso no exílio, entre suas muitas polêmicas, como a tão conhecida com Andrés Bello sobre a reforma ortográfica, Sarmiento já havia declarado, antes da publicação do Facundo, que: "No nos proponemos rehabilitar el romanticismo, porque esta es una tarea inutil; el romanticismo no expresa hoy nada y es una vulgaridad ocuparse de él como de una cosa inexistente" (El Mercurio, Valparaíso, 25 jul. 1842, in Pinilla, 1943, p.81).

De todo modo, o Facundo, e nisso a crítica coincide quase unanimemente, é um livro fundacional das letras argentinas, suas dicotomias reverberaram ao longo do século XIX e boa parte de XX e continuam vigentes em certas perspectivas de pensamento. A civilização se identifica com a Europa, especialmente a França revolucionária e a Inglaterra industrial, a ideia de progresso, as Constituições, cujo modelo são da França e dos Estados Unidos, a livre navegação dos rios e a abertura ao mercado mundial que o capitalismo do século XIX já tinha posto em funcionamento, a urbanização, a indústria, a educação pública, a defesa da propriedade privada, enfim, as leis e instituições liberais, enquanto a barbárie é a Espanha e a Inquisição, a colônia, a América virgem e sua natureza, cujos produtos são, por um lado, os pampas, o campo e os gauchos, e por outro, os candillos e o despotismo de Rosas com sua mazorca e suas montoneras, e ainda o Oriente: Tamerlão, Maomé, o mundo árabe, o fechar-se sobre si: expressa na não navegabilidade dos rios, no retrocesso, no estancamento, na estagnação, enfim, na imagem do deserto. Constrói-se uma tensão constante que, para alguns críticos, não teria uma solução dialética (Terán, 2008, cap.3), já que não haveria um herói da civilização que se opusesse à proeminência do caudilhismo, enquanto, para outros (Martínez Estrada, 1971), o modo em que se organizará a nação argentina não é senão a síntese de ambas as forças opostas. O Facundo, de todo modo, não pode, ou talvez seja melhor dizer, não deve ser definido no diapasão dos gêneros literários: romance ou novela, folhetim (e assim foi publicado originalmente), tratado sobre política argentina, manual de determinismo geográfico dos pampas, caracterização sociológica ou tipologia do gaucho, literatura de viagem, biografia de Quiroga ou de Rosas, autobiografia de Sarmiento, ensaio, panfleto político, programa liberal para deter "el mal que aqueja a la Argentina", isto é, a extensão ou a imagem do deserto, livro de história etc. Cada modalidade pode justificar-se com o próprio texto, ou a partir dele. Eis o acervo inesgotável de interpretações e leituras sempre renovadas do Facundo. Além disso, a constante mudança de registro, essa oscilação entre o biográfico, 
o científico, o meramente anedótico, o literário ou o histórico, faz de Facundo uma intrincada trama narrativa cujo vigor mereceu o esforço interpretativo tanto de seus admiradores quando de seus detratores.

De todo modo, existem duas leituras frequentes que devemos mencionar. A primeira é mais conjuntural, a leitura edípica; a segunda é imperecível, a leitura literária que outorgou ao Facundo o mote de clássico das Letras argentinas. Embora não sejam excludentes, em mais de uma ocasião, como acontece com os termos civilização e/ou barbárie, ambas as leituras foram superadas; em outras ocasiões, pelo contrário, as leituras ficaram superpostas, dando origem às melhores críticas. Avancemos nesse sentido para rever ambas variantes.

Se existe (subsiste) a possibilidade da leitura edípica, isto é, o Facundo como resposta ao enigma nacional que apresenta Sarmiento no texto, isso se deve, sobretudo, à glória do tirano Rosas, para dizê-lo com o Félix Frias, pois, a centralização do poder político em sua figura fez que as interpretações subsequentes se apoiassem, buscando legitimidade, inegavelmente no próprio nome do inimigo, embora esse ponto não resolvesse o enigma. Afinal, por mais acertada que fosse, a resposta que deu Facundo não afugentou a Quimera-Rosas. A importância do rosismo é tal que, como nota Jorge Myers (2011, p.13):

puede incluso aseverarse que durante largas décadas una porción importante de las obras de historia escritas en el pais debieron adoptar obligadamente un posicionamiento ideológico con respecto a esa sombra [la de Rosas], en un contexto donde aun el silencio estaba impregnado de significaciones.

Ora, por que é Facundo Quiroga e não Rosas o biografado? Sarmiento fugiu da sua San Juan natal, pela segunda vez, em 1840. A primeira vez, sua família teve que se deslocar até o país transandino depois de Sarmiento chamar de bandido a Facundo Quiroga em uma carta dirigida a um amigo, que foi interceptada e publicada. A segunda vez, e assim começa o Facundo, fugiu dos esbirros de Rosas, depois das acusações de Sarmiento contra o restaurador das leis. Dessa forma, a imbricação e o cruzamento de destinos, em sua dupla acepção, dos personagens do Facundo são notáveis. Sarmiento deve sair novamente da Argentina e, no exílio, para defender-se dos ataques que, dessa vez por meio da imprensa chilena cooptada por Rosas, recebe no Chile, publica sua nova defesa: Facundo. O texto começa com um episódio da vida de Sarmiento e, logo, continua com a biografia de Facundo Quiroga, para narrar as vicissitudes que levaram ao caudilhismo e ao caos nacional, concluindo com a figura de Rosas. Então, a invocação do Facundo e sua temível sombra, a narração de suas sangrentas campanhas contra os unitários em várias províncias, sua violência gratuita e seu "espírito selvagem" são um prólogo à tirania de Rosas, mais temida ainda, não só porque Rosas ainda estava vivo, mas também porque "Facundo es cruel sólo cuando la sangre se le ha venido a la cabeza y a los ojos, y ve todo colorado", enquanto Rosas "no se enfurece nunca; calcula en la quietud y en el recogimiento de su gabinete, $y$ desde allí, salen las órdenes a sus sicarios" (Sarmiento, 2006, p.215). O que em Facundo era instinto, em Rosas será método, o seu sistema. O terror como sis- 
tema político é a conclusão de Sarmiento sobre o modo usado por Rosas para administrar a Confederação. Se Sarmiento utilizou capítulos inteiros repassando a vida e a obra sanguinária, porém útil aos fins da unificação "na barbárie" das províncias do norte, empreendida pelo caudillo Facundo Quiroga, foi com o intuito de explicar como todo aquele terror converte-se em sistema com Rosas no poder, e até mesmo, tratando a morte do próprio Facundo como um ato oficial, igual a de outros tantos federais de peso que, segundo Sarmiento, poderiam ameaçar no futuro a autoridade inquestionável de Rosas. Como aprendera Rosas os métodos usados para administrar o país?: "Dios me perdone si me equivoco, pero esta idea me domina hace tiempo: en la estancia de ganados en que ha pasado toda su vida, en la Inquisición, en cuya tradición se ha educado". Daí a degola e a tortura: a Espanha medieval e o matadouro de reses: Rosas educou-se nas instituições da barbárie.

Eis o ponto central da leitura política do Facundo. A Constituição e a criação e manutenção das instituições liberais são o objetivo fundamental de todos os proscritos exilados nos seus debates da época: Alberdi em suas Bases, Echeverría em seu Dogma Socialista e, claro, Sarmiento em seu Facundo. Já antes, dizia Sarmiento na imprensa chilena: “Felices los pueblos que ya se han dado instituciones!" ("El emigrado” Mercurio, Santiago, 1841, in Sarmiento, 1948, p.23).

Rosas havia anulado a Constituição unitária que vigorava até 1835 e se negava a ceder diante do influxo constitucionalista no qual se viu envolvido todo o Ocidente na época. O dele era o método americano. O impedimento da navegação dos rios, em detrimento dos interesses estrangeiros, mas também das províncias do interior, levou a França e mais tarde a Inglaterra a realizarem um bloqueio no porto de Buenos Aires. O revisionismo histórico, desde 1930 e, sobretudo, durante o peronismo (Hernández Arregui, 2008) inverteu o panteão laico dos chamados heróis da pátria e colocou Rosas, por ter suportado o bloqueio e ganhado a disputa contra a força imperialista franco-britânica, no topo desse altar, enquanto para Sarmiento (2006, p.284): “El bloqueo francés fue la vía pública por la cual se llegó a manifestarse sin embozo el sentimiento llamado propiamente americanismo. Todo lo que de bárbaros tenemos; todo lo que nos separa de la Europa culta, se mostró desde entonces [...] organizado en sistema".

Todo o capítulo XV, que Sarmiento retirou e colocou no livro, dependendo da ocasião e do cenário político, é seu programa liberal. Ali diz que, apesar de Rosas e até mesmo por causa dele, a unidade já estava dada no território: "La idea de los unitarios está realizada; sólo está de más el tirano; el día que un buen gobierno se establezca, hallará las resistencias locales vencidas y todo dispuesto para la unión" (ibidem, p.301). Finalmente, de modo programático, Sarmiento alude à institucionalização do exército, à criação de escolas públicas, ao associacionismo, como nos Estados Unidos, a uma imprensa livre, à abertura dos portos, à livre navegação dos rios, à recepção massiva de imigrantes europeus que iriam trazer as ideias de progresso, à religião para que "moralice a los pueblos", à Constituição, ao direito à propriedade privada etc. 
Ora, entre a leitura histórico-conjuntural do Facundo e sua leitura literária, vale citar o que um contemporâneo de Sarmiento disse sobre as críticas às imprecisões que vários críticos já haviam assinalado assim que o texto foi publicado: "El Facundo mentira será siempre mejor que el Facundo verdadera historia". De todo modo, cremos que ambas as leituras não deveriam ser excludentes, pois:

La primera exigencia de la biografía, la veracidad, atributo pretendidamente cientifico, no es otra cosa que el supuesto retórico de un género literario, no menos convencional que las tres unidades de la tragedia clásica [...] Podemos por lo tanto afirmar que la verdad no es necesariamente lo contrario de la ficción, y que cuando optamos por la práctica de la ficción no lo hacemos con el propósito turbio de tergiversar la verdad. (Saer, 1997, p.10-11)

A segunda leitura, isto é, a literária, coloca o Facundo como iniciador não apenas da literatura nacional, mas também de uma maneira de escrevê-la. As discrepâncias de entendimento do texto quanto a se seria ele um claro exemplo do romantismo no Rio da Prata, leitura, por exemplo, de Halperín Donghi e de Altamirano, ou uma ponte entre a Ilustração europeia, em sua versão local, e o protopositivismo do Sarmiento de Conflicto y Armonía de las Razas en América, leitura de Sebreli, não deixam de alimentar nossa hipótese do caráter inclassificável do Facundo. O certo é que, além de cada epígrafe que abre os 15 capítulos do livro, em que os relatos de viajantes, Shakespeare, Lerminier, Chateaubriand ${ }^{2}$ se destacam, há uma série de recursos dos quais Sarmiento se vale que são claramente literários. Em primeiro lugar, a invocação que abre o texto intitulado "Introdução" é um recurso da literatura clássica (acudir aos deuses em auxílio do que virá a ser dito). Só que no Facundo, Sarmiento não recorre aos deuses, mas à sombra terrível de Facundo Quiroga. Em segundo lugar, e em relação direta com o recurso da invocação, Sarmiento utiliza a imagem de Facundo como a de um "grande homem", sendo constantes as comparações com Napoleão, e por meio dela explicará todo o período do qual se ocupa a narração. Nessa leitura romântica do Facundo está presente, também, o tópico do pars totalis, pois tendo explicado o caudilhismo, ou melhor, apenas a vida de um deles (Quiroga), explicar-se-ia a totalidade da história político-cultural da Argentina, desde a revolução de 1810 até o presente (1845).

As cenas descritivas e as narrativas se alternam ao longo do Facundo, mas, sempre que a narração se pretende histórica, nos momentos culminantes, ela recai no literário. O episódio da morte de Quiroga é exemplar. Nele Sarmiento narra com exatidão os lugares pelos quais "a partida" (o grupo de sicários que devia matar Quiroga) adianta-se para esperar o caudilho e emboscá-lo, sendo a própria emboscada descrita com detalhamento e realismo. Depois, após a morte a sangue frio de Facundo, que sucumbe ao levar um tiro no olho sem receber as explicações por ele proferidas, só resta uma criança que acompanhava a caravana de Quiroga. Trata-se, por sinal, do sobrinho do sargento da "partida" que, imediatamente, diz responder pela vida do menino. Então Santos Pérez, o assassino de Quiroga, mata o sargento a bala e depois: 
Desmontándose, toma de un brazo al niño, lo tiende en el suelo y lo degüella, a pesar de sus gemidos de niño que se ve amenazado de un peligro. Este último gemido del niño es, sin embargo, el único suplicio que martiriza a Santo Pérez; después, buyendo de las partidas que lo persiguen, oculto en las breñas de las rocas, o en los bosques enmarañados, el viento le trae al oido el gemido lastimero del niño. Si a la vacilante claridad de las estrellas se aventura a salir de su guarida, sus miradas inquietas se hunden en la oscuridad de los árboles sombrios, para cerciorarse de que no se divisa en ninguna parte el bultito blanquecino del niño; y cuando llega al lugar donde hacen encrucijada dos caminos, lo arredra ver venir, por el que él deja, al niño animando su caballo. (Sarmiento, 2006, p.254)

Acaso o martírio de Santos Pérez, a perseguição alucinatória do menino a cada passo, não é um castigo dos mais literários? Como explicar esses arroubos estéticos dentro da leitura científico-histórica do Facundo?

Ora, se até Santos Pérez, que assassinara Quiroga e degolara o menino, tem remorso, isto é, signos de civilidade, as características dos bárbaros Quiroga e Rosas, às vezes, chegam à admiração. De Rosas, Sarmiento chega a dizer que "es el primer jinete de la República Argentina, y cuando digo de la República Argentina, sospecho que de toda la tierra", e linhas depois compara-o com "Napoleón y Byron [que] padecía de estos arrebatos, de estos furores causados por el exceso de vida" (ibidem, p.208). A vida de Quiroga, diz Sarmiento, "me parece resumida en esos datos. Veo en ellos el hombre grande, el hombre de genio, a su pesar, sin saberlo él, el César, el Tamerlán, el Maboma" (ibidem, p.106). Assim a leitura romântica encontra fundamentação.

Se existe, porém, uma imagem que prevaleceu na leitura literária do $F a$ cundo é a da tipologia gaucha. É que haveria, segundo Sarmiento, quatro tipos de gauchos: o rastreador, que pode ler os signos da planície; o baqueano, cuja particularidade consiste em conhecer e reconhecer o mapa da planície até seus mais recônditos cantos; o gaucho mau, que é um outlaw nas próprias palavras de Sarmiento, aquele que está sempre fugindo da lei e que seria o signo mais visível da barbárie, ou da resistência à civilização, em termos sarmientinos; e o gaucho cantor. Este último é um dos personagens centrais da literatura argentina de quase todo o século XIX, no gênero característico chamado de gauchesca. Sarmiento indica alguns exemplos e coloca "La cautiva" de Echeverría como poema culto. Já o extenso poema Martín Fierro de José Hernández de 1872, cuja segunda parte apareceu em 1879 (La vuelta de Martín Fierro), é o momento mais acabado da gauchesca. Nessa linhagem, devemos destacar, também, o Juan Moreira, uma versão literária do gaucho mau, romance de Eduardo Gutiérrez escrito em 1879 e baseado em prontuários carcerários. Mais tarde, Leopoldo Lugones, em suas conferências reunidas em livro em 1916 sob o título El payador (isto é: o gaucho cantor), exaltará o Martín Fierro como poema épico argentino, inventando uma linhagem helênica ao gaucho para o separar da Espanha católica e dos índios, para elevá-lo à categoria de "ser nacional". Tal argumento e inversão de valores deixariam Sarmiento pasmo. 
Ora, uma leitura que equiparasse ambas as correntes seria das mais proveitosas, embora fique fora de nosso alcance neste breve percurso. Pois, cremos que a chave de tal leitura é dada pelo próprio Sarmiento na conhecida anedota pessoal com a qual abre o Facundo. Partindo pela segunda vez para o exílio chileno - vicissitude conjuntural -, Sarmiento escreve com carvão nas paredes do banheiro do Zonda, o jornal do qual era editor: On ne tue point les idées, uma citação em francês, isto é, a língua da civilização na consideração da geração de 1837. Porém, ele mesmo se encarrega de traduzi-la, já que:

El gobierno, a quien se comunicó el hecho, mandó una comisión encargada de descifrar el jeroglifico, que se decía contener desahogos innobles, insultos y amenazas. Oida la traducción "¡Y bien! - dijeron - ¿qué significa esto?” (ibidem, p.12)

E Sarmiento traduz da seguinte maneira: " $A$ los hombres se degïella; a las ideas, no". Bem, não se trata apenas, como tem-se dito, da barbarização da citação para que os esbirros de Rosas possam entender, já que a degola é uma prática gaucha para carnear animais e, como Sarmiento reiteradamente ressalta, uma prática federalista para aniquilar seus inimigos. Trata-se antes de uma apropriação, por meio da tradução da língua civilizada para outra língua, de uma língua espanhola possível, apesar de seu legado colonial, isto é, de uma língua-literária. O Facundo, dessa óptica, seria a síntese das forças opostas: civilização e barbárie. E Sarmiento, o herói que faltava à civilização, a versão local do "gênio", na acepção romântica, que se sobrepõe à sombra espectral de Facundo e a sua personificação mais temível: Rosas. Desse modo, o Facundo representa, parece-nos, a possibilidade de escrever literatura no século XIX argentino - literatura no seu mais amplo e frondoso sentido.

\section{Notas}

1 Ver a esse respeito: "El federalismo argentino en la primera mitad del siglo XIX” de José C. Chiaramonte (in Carmagnani, 1996, p.81-132).

2 Sarmiento apropria-se das citações, utiliza-as de cor, confundindo nomes e atribuindo palavras de um autor a outro (Head por Humboldt, por exemplo). Logo cita Shakespeare em francês. Sobre o particular, ver Martini Real, 1991, p.45-6).

\section{Referências}

ALTAMIRANO, C; SARLO, B. Ensayos argentinos, de Sarmiento a la vanguardia. Buenos Aires: Ariel, 1997.

CARMAGNANI, M. (Coord.) Federalismos latinoamericanos: México, Brasil, Argentina. México: Fondo de Cultura Económica, 1996.

CHIARAMONTE, J. C. Ciudades, provincias, Estados: Orígenes de la Nación Argentina (1800-1846). Buenos Aires: Ariel, 1997.

Nación y estado en Iberoamérica. Buenos Aires: Sudamericana, 2004. 
HALPERÍN DONGHI, T. Una nación para el desierto argentino. Introducción. In: Proyecto y construcción de una nación (1846-1880). Buenos Aires: Ariel, 1995.

HERNÁNDEZ ARREGUI, J. J. La formación de la conciencia nacional. Buenos Aires: Ediciones Continente, 2008.

MARTÍNEZ ESTRADA, E. Los invariantes históricos en el Facundo. Buenos Aires: Casa Pardo, 1971.

. Radiografía de la pampa. Buenos Aires: Hyspamerica, 1986.

MARTINI REAL, J. C. Notas sobre el padre en Facundo. Buenos Aires: Pierre Menard Editor, 1991.

MYERS, J. Orden y virtud. El discurso republicano en el régimen rosista. Buenos Aires: Universidad de Quilmes Editorial, 2011.

PINILLA, N. (Org.) La polémica del Romanticismo: V. F. López, D. F. Sarmiento y S. Sanfuentes. Buenos Aires: Editorial Americale, 1943. p.81.

SAER, J. J. El concepto de ficción. In: El concepto de ficción. Buenos Aires: Ariel, 1997. SARMiEnTO, D. F. Recuerdos de Provincia. Buenos Aires: Alfredo Angulo Editor, s. d. v.III.

. Mi defensa. In: Obras completas. Buenos Aires: Editorial Luz del Día, 1948. . Viajes por Europa, África y América (1845-1847). In: Obras completas. Buenos Aires: Editorial Luz del Día, 1949. v.V.

. Facundo. Buenos Aires: Longsellers, 2006.

SEBRELI, J. J. Critica de las ideas politicas argentinas. Buenos Aires: Sudamericana, 2003.

SVAMPA, M. El dilema argentino: civilización o barbarie. De sarmiento al revisionismo peronista. Buenos Aires: El Cielo por Asalto, 1994.

TERÁN, O. Historia de las ideas en la Argentina. Buenos Aires: Siglo XXI, 2008.

VERDEVOYE, P. Literatura argentina e idiosincrasia. Buenos Aires: Corregidor, 2002.

VIÑAS, D. De Sarmiento a Dios. Viajeros argentinos a USA. Buenos Aires: Sudamericana, 1998.

. Literatura argentina y politica. 2 vol. Buenos Aires: Santiago Arcos Ed., 2005.

WEINBERG. F. El Salón Literario de 1837. Buenos Aires: Hachette, 1977.

RESUMO - O artigo tem como escopo repassar o contexto histórico-político no qual surge a chamada "geração de 37 " e sua adaptação do romantismo no Rio da Prata. Para isso, analisam-se as diferentes abordagens críticas do Facundo. Civilização ou barbárie de Sarmiento, texto considerado fundador das letras argentinas, assim como as peripécias e publicações dos exilados do regime de Juan Manuel de Rosas, o caudillo a que estão dirigidas todas as críticas dos jovens românticos.

PALAVRAS-CHAVE: Romantismo argentino, Sarmiento, Facundo, Caudilhismo, Rosismo. 
ABSTRACT - The article aims to review the historical and political context in which the so-called "generation of ' 37 " arose and their adaptation of the Romantic movement in the River Plate. To that effect, we analyze the different critical approaches to the Facundo. Civilization or Barbarism, by Sarmiento, considered the founding text of Argentinean literature, as well as the adventures and publications by those exiled by the regime of Juan Manuel de Rosas, the caudillo to whom the romantic youth directed all of their criticism.

KEYWORDS: Argentinean romanticism, Sarmiento, Facundo, Caudillismo, Rosismo.

Diego A. Molina é licenciado em Letras Modernas pela Universidade de Buenos Aires, mestre em Literatura Brasileira pela USP, e doutorando em Literatura Hispano-ameri-cana também pela USP. É pesquisador no grupo de Cultura e Literatura do Instituto de Estudos Avançados da USP e bolsista da Fapesp. @ - diegomolina@usp.br

Recebido em 12.1.2013 e aceito em 30.1.2013. 